\title{
Correction to: Bacterial Diversity and Chemical Properties of Wheat Straw-Based Compost Leachate and Screening of Cellulase Producing Bacteria
}

\author{
Zivar Mohammadipour $^{1} \cdot$ Naeimeh Enayatizamir $^{1}$ (D) $\cdot$ Gholamreza Ghezelbash $^{2} \cdot$ Abdolamir Moezzi $^{1}$
}

Published online: 17 August 2020

(c) Springer Nature B.V. 2020

\section{Correction to: Waste and Biomass Valorization https://doi.org/10.1007/s12649-020-01119-w}

In the original publication of the article, the authors have inadvertently missed to include a statement in the Acknowledgement section and the corrected version is given below.

Authors would like to Thank Deputy of Research and Technology of Shahid Chamran University of Ahvaz (GN. SCU. AS98.248) and Jolgeh-y-Dez Agriculture Company, Abzy company (97.3.2.26032) for the support of this study.

Publisher's Note Springer Nature remains neutral with regard to jurisdictional claims in published maps and institutional affiliations.

The original article can be found online at https://doi.org/10.1007/ s12649-020-01119-w.

Naeimeh Enayatizamir

n.enayatzamir@scu.ac.ir

Zivar Mohammadipour

mohammadi.zivar88@gmail.com

Gholamreza Ghezelbash

gh.r.ghezelbash@gmail.com

Abdolamir Moezzi

moezzi151@scu.ac.ir

1 Soil Science and Engineering Department, Faculty of Agriculture, Shahid Chamran University of Ahvaz, Ahvaz, Iran

2 Biology Department, Faculty of Science, Shahid Chamran University of Ahvaz, Ahvaz, Iran 